\title{
Temperature Effects on Dormancy Completion of Vegetative Buds in Apple
}

\author{
Amos Naor \\ The Golan Research Institute, Kazrin 12900, Israel \\ Moshe Flaishman \\ Institute of Horticulture, Agricultural Research Organization, The Volcani Center, Bet Dagan 50250, \\ Israel \\ Raphael Stern \\ MIGAL_Galilee Technology Center, P.O. Box 90000, Kiryat Shmona 12100, Israel
}

\author{
Aharon Moshe \\ Northern R\&D, P.O. Box 90000, Kiriat Shmona12100, Israel
}

Amnon Erez

Institute of Horticulture, Agricultural Research Organization, The Volcani Center, Bet Dagan 50250, Israel

\begin{abstract}
AdDITIONAL INDEX WORDS. rest, chilling requirements, apical dominance, Malus sylvestris
ABstract. The relative contribution of various temperatures to dormancy completion of lateral vegetative apple [Malus sylvestris (L.) Mill. var. domestica (Borkh.) Mansf.] buds was studied quantitatively on whole container-grown trees. Trees were exposed continuously to 10 different temperatures and also to daily alternating temperatures in a 24 -hour cycle. In addition, fully chilled vertically and horizontally positioned shoots were compared under forcing conditions. No budbreak occurred in shoots chilled above $12.5 \mathrm{O}$. There was a steep increase in budbreak as the chilling temperature fell from 12.5 to $7.5 \mathrm{C}$. There was little difference in the level of budbreak on shoots chilled between 7.5 and $0 \circ \mathrm{C}$. The relative contribution of temperature to chilling accumulation in apple found in our study differs from what has been proposed for stone fruit and for apple in previous studies, especially at temperatures $<6{ }^{\circ} \mathrm{C}$. The length of exposure to forcing conditions required to initiate budbreak diminished as the chilling temperature was reduced. No additional budbreak was apparent on shoots chilled longer than 2100 chilling hours. The chilling requirement found here for lateral vegetative buds is much higher than that needed for terminal vegetative and flower buds. Trees that were exposed to daily alternating temperatures had lower levels of budbreak when the high temperature in the diurnal cycle was greater than $14{ }^{\circ} \mathrm{C}$. Practically no budbreak was apparent on trees that were exposed to diurnal cycles with a high temperature of 20 ${ }^{\circ} \mathrm{C}$ for 8 hours. Budbreak on horizontally positioned trees was more than twice that on the vertically positioned trees, emphasizing the magnitude of the apical dominance effect and its strong masking of the chilling effect on lateral buds in vertically grown apple trees. Based on the data collected here we propose a new response curve for vegetative budbreak in 'Golden Delicious' apple, within a temperature range between 0 to 15 'C.
\end{abstract}

Buds of most temperate-zone deciduous trees have a dormancy period in the winter. Low temperatures are the most significant factor affecting dormancy completion, although, there are indications that heat, light intensity, and mist, during the endodormancy phase affect dormancy completion to a certain extent (Chandler, 1960; Erez et al., 1966; Erez et al., 1968; Freeman and Martin, 1981).

Knowing the exact response of apple (Malus sylvestris var. domestica) buds to temperature is important for a basic understanding of dormancy and for the practical application of dormancy release or bloom delay techniques. Spring frost may cause severe damage to flowers and young foliage in temperate zones; therefore, prediction of the date of budbreak is an important issue for growers in those regions. Budbreak is affected by two temperature-dependent processes: a) the accumulation of chilling to the level required for dormancy completion; and b) the accumulation of the heat units required for the buds to develop to bloom and foliation. These two processes were shown to be interdependent, i.e., fewer degree-days of heating are required as the previously accumulated chilling increases (Couvillon and Erez, 1985a). In warm regions, temperatures in the winter are not low enough, or the duration of exposure is not

Received for publication 23 Oct. 2002. Accepted for publication 3 Apr. 2002. long enough, resulting in partial dormancy completion. In regions that receive insufficient chilling, growers can achieve sufficient budbreak by spraying trees with dormancy-breaking chemicals during the winter (Samish, 1954). Chilling requirements differ among cultivars buteven within a cultivar, there are wide differences in chilling requirements between bud types. For example, lateral vegetative buds have a high chilling requirement while terminal vegetative and floral buds have a low chilling requirement (Erez, 2000; Samish and Lavee, 1962). In apple, most flowers are borne as mixed terminal buds, which have a much lower chilling requirement than lateral vegetative buds (Samish and Lavee, 1962), thus some terminal bearing apple cultivars can be grown in the tropics (Edwards, 1990; Janick, 1974). Also, in a given cultivar, a correlation exists between the bud chilling requirement and shoot vigor (Erez, 2000). In warm regions, modeling the effect of temperature on chilling accumulation and the response of various bud types to chilling may enable the growers to optimize the timing of the application of dormancy-breaking chemicals as well as aid in cultivar selection for a specific site.

Limited information is available regarding the effect of temperature on dormancy completion of apple buds. The experimental data on the response of apple buds to different temperatures during 
dormancy were accumulated mainly in field studies (Anderson et al., 1990; del-Real-Laborde, 1987; del Real-Laborde et al., 1990; Hauagge and Cummins, 1991; Paiva and Robitaille, 1978; Shaltout and Unrath, 1983), and the temperature response curve was derived from the best fit of percentage budbreak to field temperature records (Shaltout and Unrath, 1983). Those studies that have been conducted under controlled environments (Mauget and Rageau, 1988; Swartz and Powell, 1981; Thompson et al., 1975; Young and Werner, 1984; 1985; ) utilized a limited number of temperature treatments. Most studies addressed budbreak of either terminal or flower buds (Anderson et al., 1990; Hauagge and Cummins, 1991; Shaltout and Unrath, 1983) or of all buds (del Real-Laborde et al., 1990; Paiva and Robitaille, 1978; Young and Werner, 1984; 1985). Only limited information is available regarding temperature effects on dormancy release of apple vegetative axillary buds (Hauagge and Cummins, 1991; Paiva and Robitaille, 1978; Thompson et al., 1975). In most cases bud forcing was applied to either excised shoots or single node cuttings (Crabbe and Barnola, 1996), and only in limited number of cases were whole trees used (Swartz and Powell, 1981; Thompson et al., 1975; Young and Werner, 1984, 1985;). Data collected from excised branches might be inconclusive, because of the possible dormancy release effect of the wound on adjacent buds (Paiva and Robitaille, 1978).

Most of the dormancy completion models were developed using stone fruit. In early models the summation of time (hours) below $7.2^{\circ} \mathrm{C}$ or between 0 and $7.2^{\circ} \mathrm{C}$ (Weinberger, 1950) was used to predict dormancy completion. Later, in the Utah model for peach (Richardson et al., 1974) the temperature used for the maximum contribution to dormancy completion were between 2.5 and $9.1^{\circ} \mathrm{C}$; the rest completion decreased to zero below 1.4 or above $12.5^{\circ} \mathrm{C}$ and negative chilling hours were accumulated above $16^{\circ} \mathrm{C}$. A similar model was proposed for apple (Shaltout and Unrath, 1983). However, the Utah model did not accurately predict dormancy completion and bloom for apple in warm (Erez et al., 1990) and temperate (Anderson et al., 1990; Shaltout and Unrath, 1983) climates.

Cyclic exposure to low and moderate temperatures was found to be more effective for dormancy completion than continuous exposure to low temperatures, in peach (Erez and Couvillon, 1987) and apricot (Gurriero et al., 1985). This synergistic effect was incorporated into a dynamic model for peach (Fishman et al., 1987), which also proposed that chilling hours are accumulated in quotas, and that once a quota was completed its effect was fixed and could not be cancelled by subsequent high temperatures. However, the use of the peach dynamic model (Erez et al., 1988; Fishman et al., 1987) to predict dormancy completion of vegetative apple buds in Israel resulted in an overestimation of chilling effect, i.e., poorer budbreak occurred than was predicted (unpublished data).

The limited information on the response of apple buds to temperature effects on endodormant buds, and the lack of uniformity among the various experimental parameters used in past studies in dormancy in apple led us to examine the effects of different temperature regimes on budbreak in apple. We undertook to quantify the relative contribution of temperature on dormancy completion of both apple vegetative and flower buds on whole trees grown in containers. In the present study we report on vegetative axillary buds.

\section{Materials and Methods}

Plant materials. 'Golden Delicious' grafted onto local rootstock (Hashabi) were grown in the nursery in plastic bags for 1 year. During the second spring the trees were transferred to a tuff-peat mixture (7:3 ratio) in a 7-1 container. The trees were pruned $40 \mathrm{~cm}$ above the graft union and three shoots were allowed to grow vertically. The trees were placed in temperature-controlled dark chambers in early November, before any chilling had accumulated.

ConTrolled ENVIRONMENT. Ten $1.5 \times 1.5 \times 2.0 \mathrm{~m}$ temperaturecontrolled chambers were used for the experiments. Air temperature was measured with thermocouples (PT100), and was controlled by an El-203 instrument (Eldar, Yad Mordechai, Israel). The temperature controller maintained the designated temperature within $\pm 1{ }^{\circ} \mathrm{C}$. After the trees had received the designated temperature treatments they were moved to forcing chambers. The temperature in the forcing chambers was $22 \pm 1.5^{\circ} \mathrm{C}$ and the photoperiod was $16 \mathrm{~h}$ light and $8 \mathrm{~h}$ dark. The trees were irrigated periodically and the floor of the forcing room was wetted frequently to maintain high humidity, to avoid bud desiccation.

EXPERIMENT 1. The temperatures in the chambers were set to 0 , $2,4,6,8,10,12,14,17$ and $20^{\circ} \mathrm{C}$ in 1999 , and to $0,2.5,5,7.5,10$, 12.5 , and $15^{\circ} \mathrm{C}$ in 2000 . Nine trees (replications) from each treatment were transferred to forcing conditions from each chamber after the accumulation of 2050 chilling $\mathrm{h}$ in the temperature-controlled chambers in 1999; and after 1500, 1800, 2100, and 2400 chilling $\mathrm{h}$ in 2000. On transfer to forcing temperatures, the non-lignified distal tip of the shoots was removed. Percentage budbreak was counted after $\approx 21, \approx 31$, and $\approx 40 \mathrm{~d}$ under forcing conditions. The trees were placed in an upright position during the forcing period in 1999. A few trees were placed horizontally during forcing for comparison purposes, which resulted in increased budbreak over vertically, oriented trees (data not shown). Thus, in order to avoid a possible suppression of budbreak due to apical dominance, all trees in the 2000 study were placed horizontally during the forcing period. No budbreak occurred in the lower part (ventral) of the horizontal shoots, probably due to apical dominance, therefore only buds on the upper (dorsal) and side parts of the shoots (70\% of total buds) were counted.

EXPERIMENT 2. Eight trees (replications) per treatment were

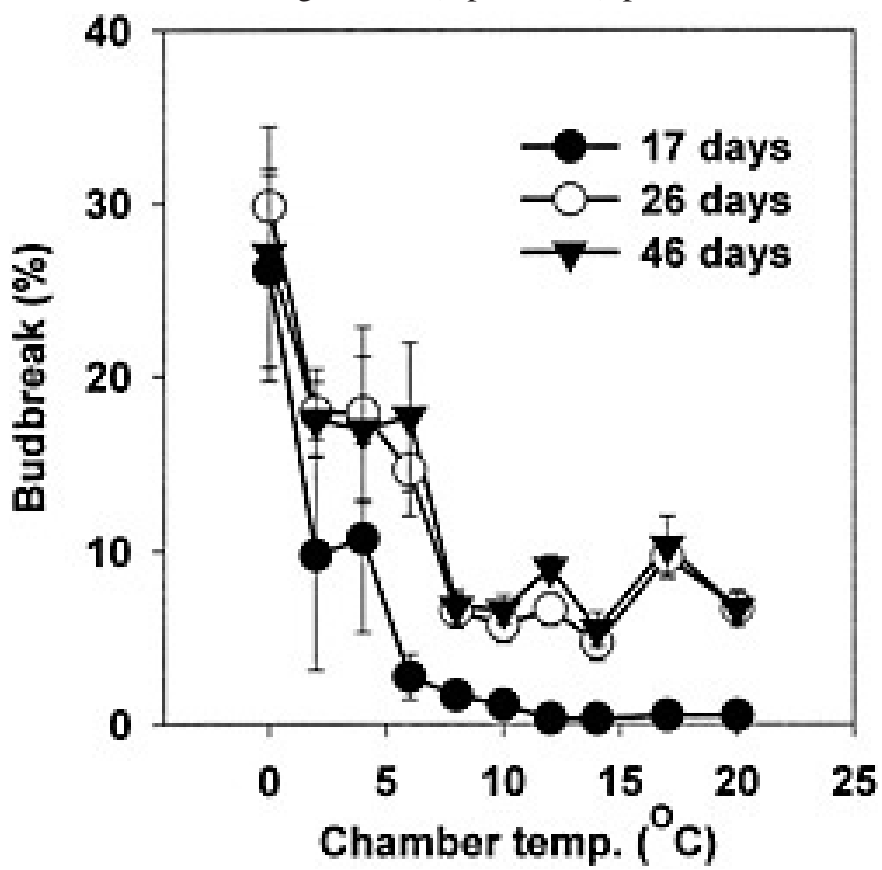

Fig. 1. Vegetative budbreak (\%) of 1-year-old 'Golden Delicious' apple shoots, as a function of exposure temperature in 1999. Trees were exposed to various temperatures for $2050 \mathrm{~h}$ and budbreak was determined after 17,26 , and $46 \mathrm{~d}$ of forcing at $22{ }^{\circ} \mathrm{C}$. Trees were placed in a vertical position during forcing. Bars denote standard error; $\mathrm{n}=9$. 


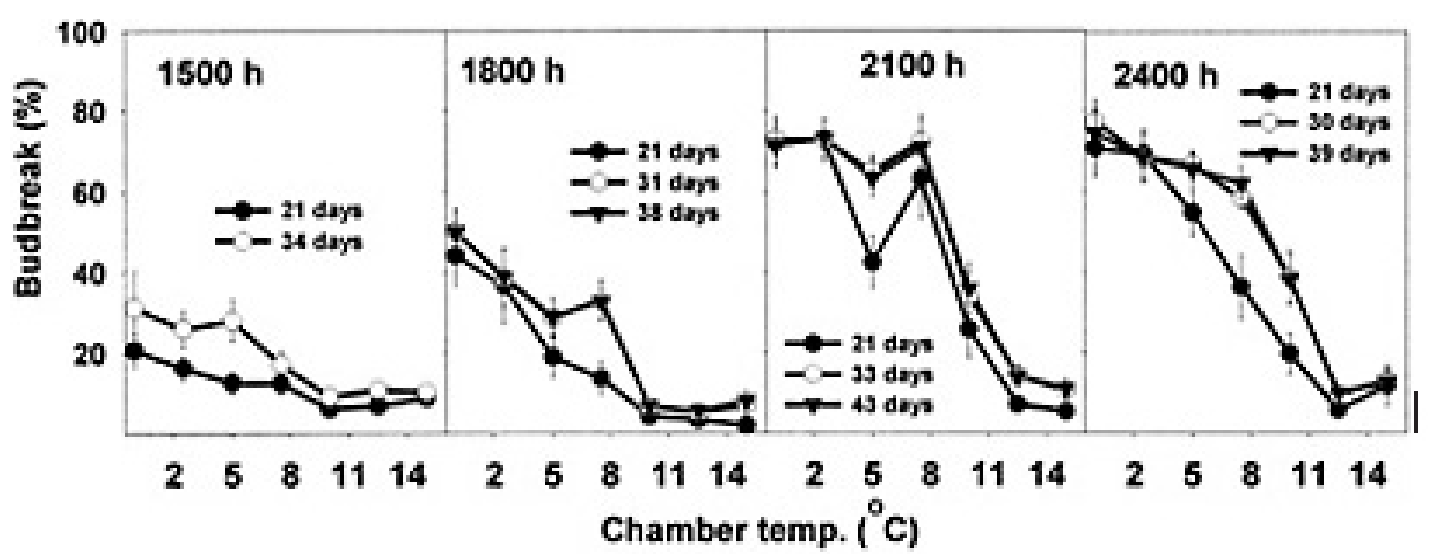

HR, whereas buds exposed to 12.5 and $15^{\circ} \mathrm{C}$, had no increase in budbreak as the duration of chilling exposure increased from 1500 to 2400 h. Budbreak did not increase in any treatment above 2100 $\mathrm{h}$ of exposure.

EXPERIMENT 2. In this diurnal temperature cycling experiment, the trees were exposed to $6^{\circ} \mathrm{C}$ for $16 \mathrm{~h}$ and to 14,17 or $20^{\circ} \mathrm{C}$ for $8 \mathrm{~h}$ per a $24 \mathrm{~h}$ period $\left(6 / 14{ }^{\circ} \mathrm{C}, 6 / 17\right.$ ${ }^{\circ} \mathrm{C}$ and $6 / 20{ }^{\circ} \mathrm{C}$ ). In diurnal

Fig. 2, Vegetative budbreak (\%) of 1-year-old 'Golden Delicious' apple shoots as a function of exposure temperature in 2000 . Trees were exposed to various temperatures for $1500,1800,2100$, and $2400 \mathrm{~h}$ and budbreak was determined afte $\approx 20,30$, and $40 \mathrm{~d}$ of forcing at chamber temperature $22^{\circ} \mathrm{C}$. Trees were placed in a horizontal position during forcing. Bars denote standard error; $n=9$.

placed in three temperature-controlled chambers set so that temperatures alternated in a diurnal cycle. In all chambers, $6{ }^{\circ} \mathrm{C}$ was maintained for $16 \mathrm{~h}$, while for $8 \mathrm{~h}$ temperatures were set to 14,17 or $20^{\circ} \mathrm{C}$. The trees were placed horizontally in the forcing room after the accumulation of $2100 \mathrm{~h} \square 6^{\circ} \mathrm{C}$. Budbreak was measured after 11, 20, 30, and $40 \mathrm{~d}$ of forcing.

EXPERIMENT 3. To evaluate the effect of apical dominance on budbreak, 20 trees were placed outdoors in early November 2001 for chilling accumulation at the Fichman Experimental Station $\left(33^{\circ} \mathrm{N}\right.$, $\left.36^{\circ} \mathrm{E}\right), 1000 \mathrm{~m}$ above mean sea level. The trees were transferred to the forcing room on 17 Feb. 2002; Ten trees were positioned vertically and the balance (10 trees) were positioned horizontally. Budbreak was counted after 7, 14, 20, 30, and $40 \mathrm{~d}$.

Statistical analysis. The trees were placed in a complete randomly design in the forcing chambers. Average budbreak on each tree was calculated before the mean and standard error of each treatment were calculated.

\section{Results}

EXPERIMENT 1. In 1999 budbreak increased with decreasing temperature between 8 and $6{ }^{\circ} \mathrm{C}$. There was no significant difference in budbreak between temperatures of $6^{\circ} \mathrm{C}$ and below (Fig. 1); maximum budbreak occurred after $26 \mathrm{~d}$ at $0{ }^{\circ} \mathrm{C}$ in 1999 ; $\approx 10 \%$ budbreak occurred in the $>8{ }^{\circ} \mathrm{C}$ treatments (Fig. 1) in buds adjacent to the excised terminal portion of the shoot. Budbreak increased as the forcing duration increased up to $30 \mathrm{~d}$ in 2000 ; $\approx 10 \%$ budbreak was apparent at 12.5 and $15{ }^{\circ} \mathrm{C}$ after 2100 and $2400 \mathrm{~h}$ of chilling (Fig. 2). These data are similar to that for the high temperatures in 1999 (Fig. 1). Budbreak values were higher in 2000 than in 1999 due to the horizontal placement of the trees. A significant increase in budbreak occurred in trees exposed to $7.5^{\circ} \mathrm{C}$ as compared to those exposed to $12.5^{\circ} \mathrm{C}$. There was a significant increase in budbreak on trees exposed to 0 and $2.5^{\circ} \mathrm{C}$ compared to those exposed to $7.5^{\circ} \mathrm{C}$ (Fig. 2). Trees that were exposed to 0 and $2.5^{\circ} \mathrm{C}$ for $2400 \mathrm{~h}$ reached maximum budbreak $21 \mathrm{~d}$ following initiation of forcing (Fig. 2), whereas buds exposed to 7.5 and 10 ${ }^{\circ} \mathrm{C}$ for $2400 \mathrm{~h}$ required $30 \mathrm{~d}$ to reach maximum budbreak. Budbreak of trees exposed to $0,2.5$, and $7.5^{\circ} \mathrm{C}$ increased from $\approx 30 \%$ to $\approx 70 \%$, as the duration of exposure to chilling increased from 1500 to 2100 h (Fig. 3). At $10^{\circ} \mathrm{C}$ budbreak increased from $6.5 \%$ to $33 \%$ as the exposure to chilling increased from 1800 to 2100

cycles consisting of $6 / 14,6 / 17$ and $6 / 20^{\circ} \mathrm{C}$, budbreak levels of $72 \%$, $33 \%$, and $9.5 \%$, respectively, were obtained (Fig. 4). Budbreak increased as the duration of forcing increased in all three treatments. A rapid rate of budbreak was noted in buds chilled in the $6 / 14^{\circ} \mathrm{C}$ cycle and forced for $10 \mathrm{~d}$ (Fig. 4). The interpolated budbreak level of trees that were continuously exposed to $6^{\circ} \mathrm{C}$ (Figs. 2 and 4 ) was lower than that of the $6 / 14{ }^{\circ} \mathrm{C}$ cycle treatment.

EXPERIMENT 3. A comparison of the levels of budbreak, in identically chilled trees that were positioned horizontally or vertically during forcing showed that the position in which the trees were forced had a major effect on budbreak. After $30 \mathrm{~d}$ of forcing, the proportion of vegetative buds breaking in the horizontally positioned trees was more than twice that found in the vertically positioned trees (Fig 5). This effect was attributed to apical dominance.

\section{Discussion}

Strong apical dominance in apples coupled with the low chilling requirements of the terminal bud combine to mask chilling effects on lateral buds. Our data suggest that this masking effect can be avoided by using horizontally oriented branches. The dramatic apical dominance effect found in our study is higher than what

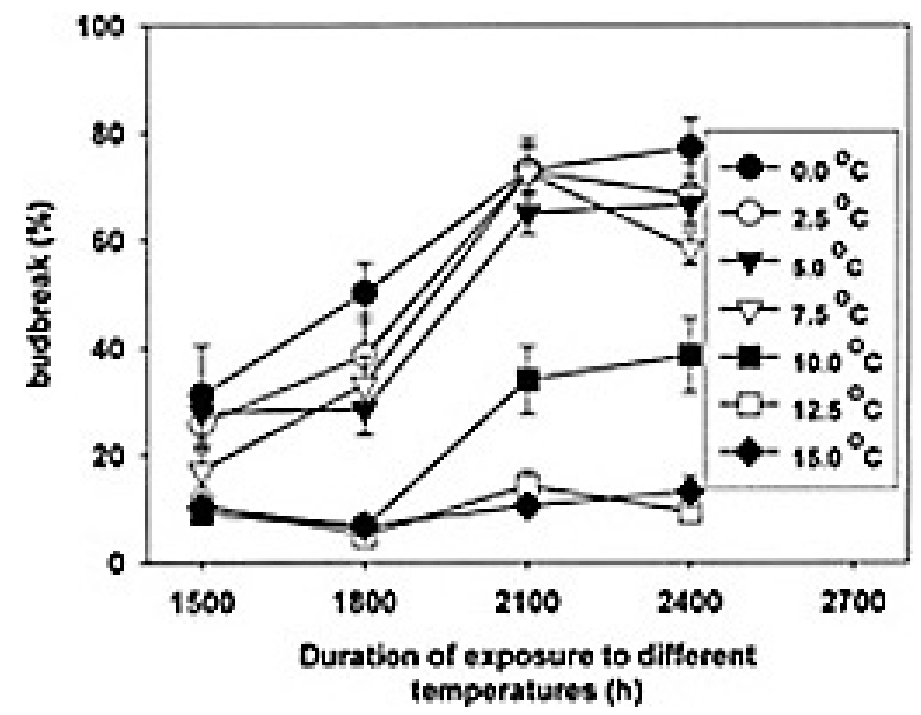

Fig. 3. Vegetative budbreak (\%) of 1-year-old 'Golden Delicious' apple shoots as a function of the duration of exposure to various temperatures in 2000. Budbreak was determined after $\approx 21, \approx 31$, and $\approx 40 \mathrm{~d}$ of forcing at chamber temperature $22{ }^{\circ} \mathrm{C}$. Trees were placed in a horizontal position during forcing. Bars denote standard error; $\mathrm{n}=9$. 


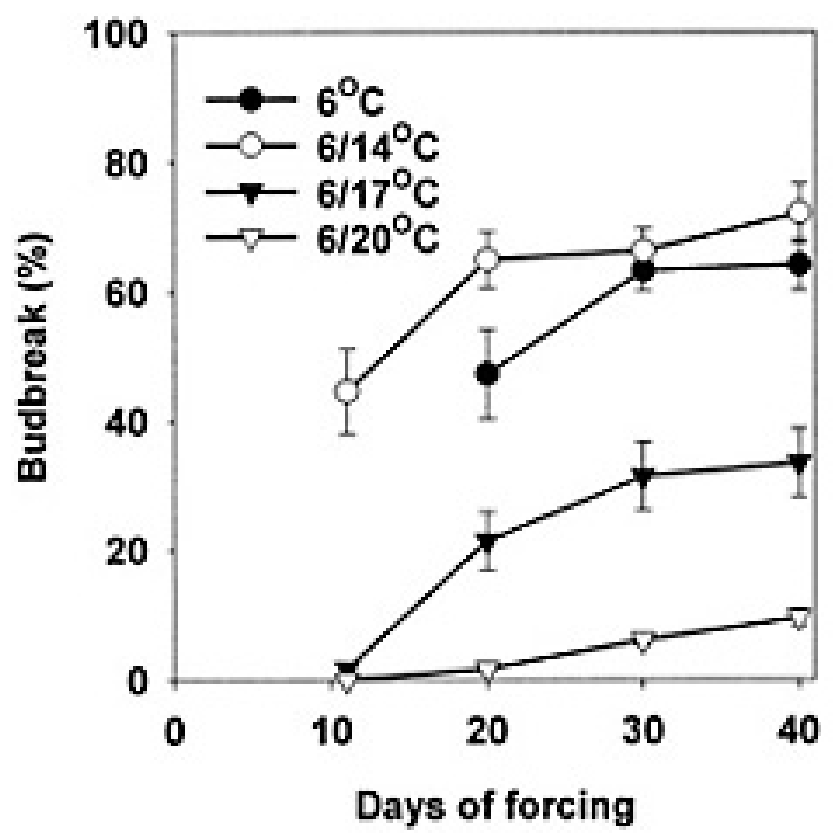

Fig. 4. Cumulative vegetative budbreak (\%) of 1-year-old 'Golden Delicious' apple shoots after exposure to alternating temperatures in a daily cycle $(6 / 14$ ${ }^{\circ} \mathrm{C}, 6 / 17{ }^{\circ} \mathrm{C}$, and $6 / 20^{\circ} \mathrm{C}$ ) for $2100 \mathrm{~h}$ in 2000 . Trees were exposed to the warm temperatures $\left(14,17\right.$, and $\left.20^{\circ} \mathrm{C}\right)$ for $8 \mathrm{~h}$ and to $6^{\circ} \mathrm{C}$ for $16 \mathrm{~h}$. Budbreak was determined after $11,20,30$, and $40 \mathrm{~d}$ of forcing at $22{ }^{\circ} \mathrm{C}$. In addition, the interpolated budbreak of trees that were continuously exposed to $6^{\circ} \mathrm{C}$, followed by 20,30 , and $40 \mathrm{~d}$ in forcing, is presented for comparison. Trees were placed horizontally during forcing. Bars denote standard error; $\mathrm{n}=8$.

has been observed under natural conditions. This difference could be due to the rapid accumulation of growing degree-hours under continuous exposure to $22^{\circ} \mathrm{C}$ during forcing which increased the gap between the timing of terminal and lateral budbreak.

During both years of the study, $\approx 10 \%$ budbreak was apparent at temperatures $>10^{\circ} \mathrm{C}$ (Figs. 1 and 2), independent of the orientation of the shoots. Budbreak on shoots exposed to temperatures greater than $10^{\circ} \mathrm{C}$ did not respond to increasing duration of exposure

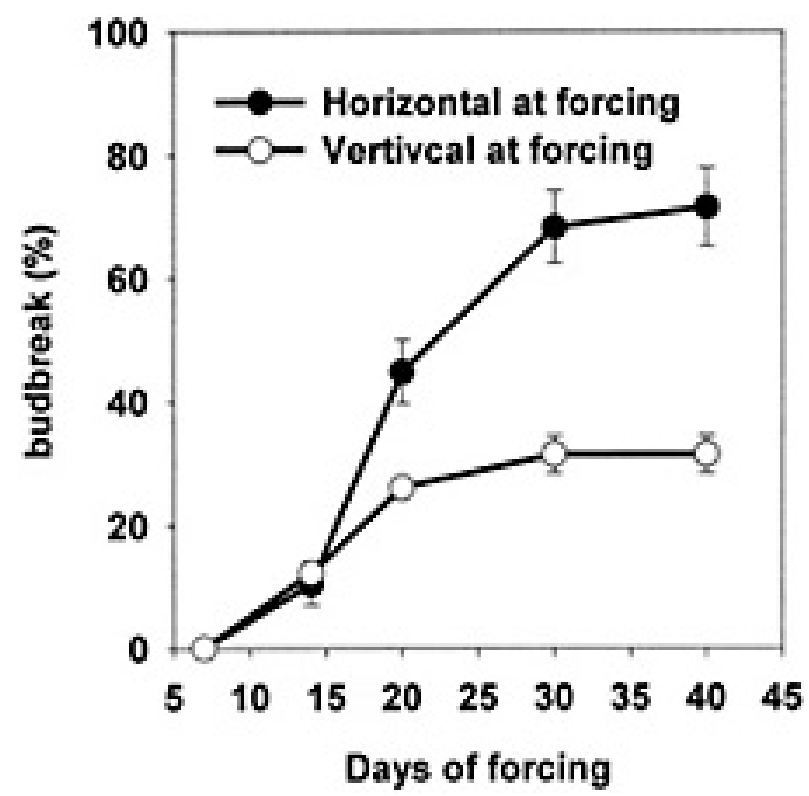

Fig. 5. Comparison of the cumulative level of lateral budbreak of 'Golden Delicious' apple trees that were forced in a vertical and horizontal positions. Bars denote standard error; $\mathrm{n}=10$. $(\geq 2100$ HR) (Fig. 3). Since the buds that broke were in the immediate vicinity of the cut it is suggested that the $10 \%$ budbreak of buds exposed to $10^{\circ} \mathrm{C}$ and greater was a response to the wound, an effect which is known to break dormancy (Paiva and Robitaille, 1978). Past interpretations of the response of detached shoots (Hauagge and Cummins, 1991; Mauget and Rageau, 1988; Paiva and Robitaille, 1978; Shaltout and Unrath, 1983) to chilling might be distorted by the effect of the wound in breaking bud dormancy. In studies utilizing detached shoots for chilling, a baseline must be established to determine the magnitude of the wound effect on budbreak (Figs. 1, 2, and 3). Selecting long shoots should minimize the proportion of budbreak attributable to the wound effect, and the use of whole trees, as in the present study, seems to provide the least disturbed conditions.

Maximal budbreak in horizontally placed trees, occurred after exposure to chilling for $2100 \mathrm{~h}$, indicating that the endodormancy of vegetative buds was completed between 1800 and $2100 \mathrm{~h}$ of chilling. Since budbreak of trees chilled at $10^{\circ} \mathrm{C}$ did not increase following $2100 \mathrm{~h}$ or greater of chilling, temperatures of $10^{\circ} \mathrm{C}$ or greater are not efficient chilling temperatures. Hauagge and Cummins (1991) using detached shoots reported chilling requirements similar to what we found for apple. Swartz and Powell (1981) and Thompson et al (1975) reported slightly higher or lower temperatures than what was found in our study. Swartz and Powell (1981) used detached shoots, but provided no information regarding the type of bud used; therefore, the possibility that they examined a different type of bud than used in our study cannot be excluded. A much lower chilling requirement for vegetative buds was reported by del Real-Laborde et al. (1990) than what was reported in our study; however, the cultivar used was not mentioned, thus one cannot exclude the possibility that a low chilling cultivar was used which could explain the difference between the two studies. Our data agree with those of Hauagge and Cummins (1991) and Thompson et al (1975) and may suggest that the chilling requirement of vegetative buds is much higher than that of flower buds. This would be consistent with the lower level of budbreak of vegetative buds compare to that of flower buds experienced in warm regions (Samish and Lavee, 1962). Limited chilling will allow terminal buds to break, resulting in terminal fruiting in cultivars having mixed terminal buds. This would limit the yield as well as the quality of the resulting apple fruit. Therefore, for acceptable apple production performance in warm regions, the completion of endodormancy of vegetative buds is the limiting condition, and not that of flower buds, which have a lower chilling requirement. It is of major importance to know the chilling threshold for vegetative buds that ensures the development of enough vegetative growing points to support fruit-bearing spurs.

The relative budbreak in the $6 / 14^{\circ} \mathrm{C}$ treatment was $15 \%$ higher than the interpolated budbreak at a continuous exposure to $6{ }^{\circ} \mathrm{C}$ (Fig. 4). This indicates a possible promoting effect of the alternating day/night temperatures at forcing, as has been shown for moderate temperatures in peach (Erez and Couvillon, 1987) and apricot (Guerriero et al., 1985). Cyclic treatments $\left(6 / 17^{\circ} \mathrm{C}, 6 / 20^{\circ} \mathrm{C}\right)$ produced a negative effect on budbreak as compared to continuous chilling. Cycles of $6 / 20^{\circ} \mathrm{C}$ produced a greater negative effect than $6 / 17^{\circ} \mathrm{C}$, which is in agreement with the data of Thompson et al. (1975). The negative chilling response of apple to high temperatures was apparent at $17^{\circ} \mathrm{C}$, lower than reported for peach (Couvillon and Erez 1985b). The negating effect of the warm temperatures in the present study was restricted to $8 \mathrm{~h}$ of higher temperature in a 24-h cycle. The response to daily alternating temperatures has been reported to vary in the course of exposure to the warm temperature (Couvillon 


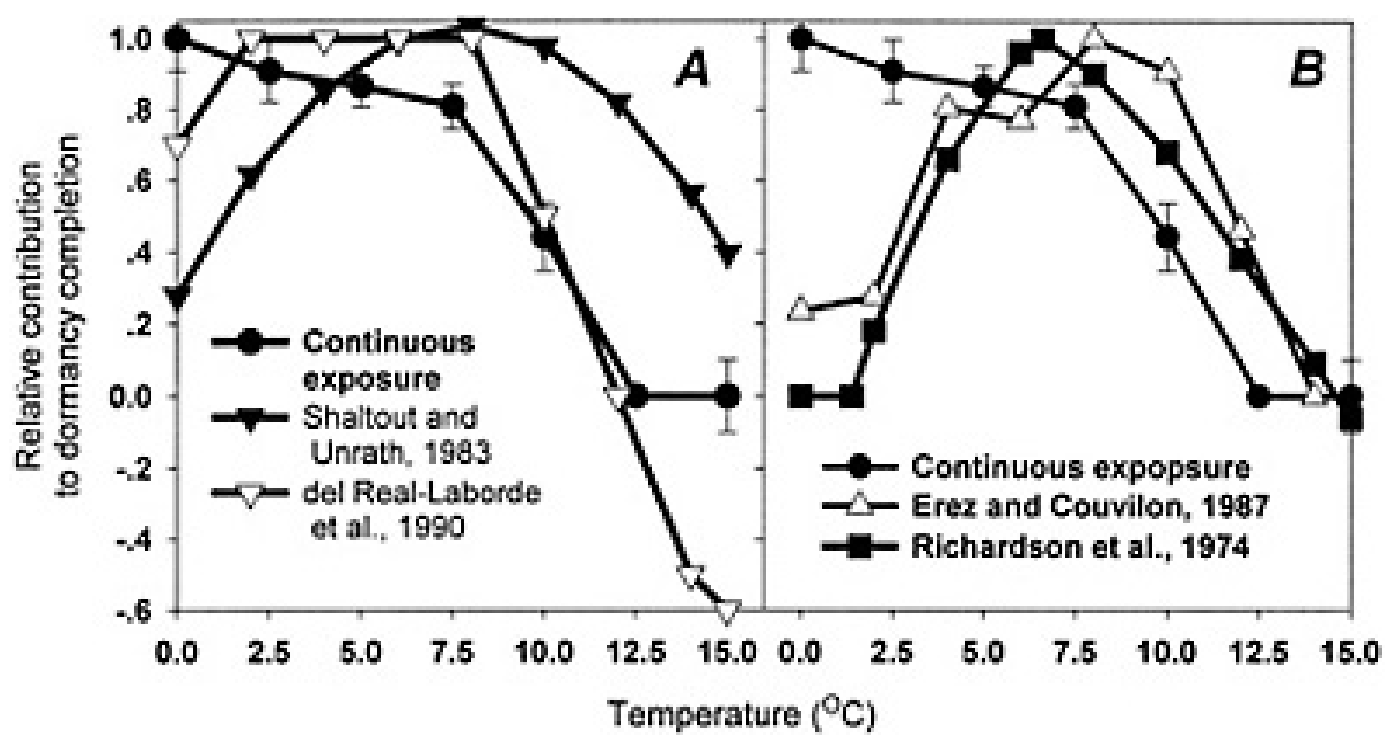

Fig. 6. The relative contributions of various temperatures to dormancy completion based on vegetative budbreak after $2400 \mathrm{~h}$ of continuous exposure to temperatures ranging from 0 to $15^{\circ} \mathrm{C}$, followed by $30 \mathrm{~d}$ in forcing conditions. A value of 1 was set to $0^{\circ} \mathrm{C}$ and the relative contribution of other temperatures was calculated accordingly. Bars denote standard error. Our data are compared with dormancy completion models for apple flower buds (Shaltout and Unrath, 1983) and for apple seeds (del Real-Laborde, et al., 1990) at 50\% accumulation of their chilling requirement (A), and with two models for peach buds (Erez and Couvillon, 1987; Richardson et al., 1974) (B).

and Erez, 1985b), and there is a quota of accumulated chilling hours, whose effect cannot be negated by subsequent exposure to higher temperatures (Fishman et al., 1987). Additional models developed for apple (del Real-Laborde et al., 1990; Shaltout and Unrath, 1983) did not take into consideration the complex interactions of daily alternating temperatures. There is a need for more detailed study of the interactions of daily alternating temperatures, and the response to temperature throughout the endodormant period (del Real-Laborde et al., 1990; Thompson et al., 1975; Young, 1992). Also, interactions between root and shoot temperatures (Young, 1988; Young et al., 1986), need to be incorporated into a dormancy completion model for vegetative buds in apple.

Based on our data (Fig. 2), a temperature-response curve was constructed for vegetative budbreak in 'Golden Delicious' apple (Fig. 6). Budbreak after $2400 \mathrm{~h}$ of exposure of trees to temperatures ranging from 0 to $15^{\circ} \mathrm{C}$, and followed by $30 \mathrm{~d}$ of forcing (Fig. 2) was used. The level of budbreak that was attributed to the effect imposed by the terminal cuts was subtracted from each budbreak value. The budbreak on shoots chilled at $0^{\circ} \mathrm{C}$, at which the maximal level was obtained, was given a designation of 1 , and the relative values at other temperatures were calculated accordingly. Our data (Fig. 6A) are close to the findings for apple seeds (del Real-Laborde, 1990) at $50 \%$ accumulation of their chilling requirement. Also, in our study apple vegetative buds were more responsive to temperatures $<6$ ${ }^{\circ} \mathrm{C}$ and less responsive to temperatures $>6^{\circ} \mathrm{C}$ than is predicted by the model proposed for apple by Shaltout and Unrath (1983) (Fig. 6A). Our data are also in agreement with the data of Thompson et al. (1975) which showed in apple that $2^{\circ} \mathrm{C}$ was the most efficient temperature, with reduced efficiency at higher temperatures $(76 \%$ at $6^{\circ} \mathrm{C}$ and $39 \%$ at $10{ }^{\circ} \mathrm{C}$ ).

Our data suggest that vegetative buds of apple are more responsive to lower temperatures than those of peach (Erez and Couvillon, 1987;
Richardson et al., 1974) (Fig. 6B). The proposed temperature response curve for vegetative budbreak in 'Golden Delicious' apple (Fig. 6) may serve to model the dormancy break of lateral vegetative buds. This response curve should be incorporated into a whole-tree endodormancy completion model, which would account for the differing temperature response curves of vegetative and flower buds in the process of dormancy completion.

\section{Literature Cited}

Anderson, J.L., A. H. Hatch, S.C. Seeley, R. Renquist, and M. K. Rogoyski. 1990. Delayed foliation of apples and cherries in Utah and Colorado during 1989.

Acta Hort. 276:193-199

Chandler, W.H. 1960. Some studies of rest in apple buds. Proc. Amer. Soc. Hort. Sci. 76:1-10.

Couvillon, G.A. and A. Erez. 1985a. The influence of prolonged exposure to chilling temperatures on budbreak and heat requirement for bloom of several fruit species. J. Amer. Soc. Hort. Sci. 110:47-50.

Couvillon, G.A. and A. Erez. 1985b. Effect of level and duration of high temperatures on rest in the peach. J. Amer. Soc. Hort. Sci. 110: 579-581.

Crabbe, J. and P. Barnola. 1996. A new conceptual approach to bud dormancy in woody plants, p. 115-132. In: G.A. Lang (ed.). Plant dormancy, physiology, biochemistry and molecular biology. CAB Intl., London. del Real-Laborde, J.I. 1987. Estimating chill units at low latitudes. HortScience 22:1227-1231.

del Real-Laborde, J.I., J.L. Anderson, and S.D. Seeley. 1990. An apple tree dormancy model for subtropical conditions. Acta Hort. 276:183-191.

Edwards, G.R. 1990. Ten years' experience with temperate fruit in the Tropics. Acta Hort. 279:47-51.

Erez A. 2000. Bud dormancy: Phenomenon, problems and solutions in the tropics and subtropics, p.17-48. In: A. Erez (ed.). Temperate fruit crops in warm climates. Kluwer Academic Publishers, Dordrecht, The Netherlands.

Erez, A. and G.A. Couvillon. 1987. Characterization of the influence of moderate temperatures on rest completion in peach. J. Amer. Soc. Hort. Sci. 112:677-680

Erez, A., S. Fishman, Z. Gat, and G.A. Couvillon. 1988. Evaluation of winter climate for breaking bud rest using the dynamic model. Acta Hort. 232:76-89.

Erez,A., S. Fishman, G.C.Linsley-Noakes, and P.Allan. 1990. The dynamic model for rest completion in peach buds. Acta Hort. 276:165-174.

Erez,A., S. Lavee, and R.M. Samish. 1968. The effect of limitation in light during the rest period on leaf budbreak of the peach (Prunus persica) Physiol. Plant. 21:759-764.

Erez, A., R.M. Samish, and S. Lavee. 1966. The role of light in leaf and flower bud break of the peach (Prunus persica). Physiol. Plant. 19: 650-659.

Fishman, S., A. Erez, and G.A. Couvillon. 1987. The temperature dependence of dormancy breaking in plants: Mathematical analysis of a two-step model involving a cooperative transition. J. Theor. Biol. 124: 473-483.

Freeman, M.W., and G.C. Martin. 1981 Peach floral budbreak and abscisic acid content as affected by mist, light and temperature during rest. J. Amer. Soc. Hort. Sci. 106:333-336.

Guerriero, R.S. E.P. Indiogine, and G. Scalabrelli. 1985. The effect of 
cyclic and constant temperature in fulfilling the chilling requirement of two apricot cultivars. Acta Hort. 192:41-48.

Hauagge, R. and J.N. Cummins. 1991. Phenotypic variation of length of bud dormancy in apple cultivars and related Malus species. J. Amer. Soc. Hort. Sci. 116:100-106.

Janick, J. 1974. The apple in Java. HortScience 9:13-15.

Mauget, J.C. and R. Rageau. 1988. Bud dormancy and adaptation of apple tree to mild winter climates. Acta Hort. 232:101-108.

Paiva, E., and H.A. Robitaille. 1978. Breaking bud rest on detached apple shoots: Effect of wounding and ethylene. J. Amer. Soc. Hort. Sci. 103: 101-104.

Richardson, E.A., S.D. Seeley, and D.R. Walker. 1974. A model for estimating the completion of rest for 'Redhaven' and 'Elberta' peach trees. Hortscience 9:331-332.

Samish, R.M. 1954. Dormancy in woody plants. Annu. Rev. Plant Physiol. 5:183-203.

Samish, R.M. and S. Lavee. 1962. The chilling requirement of fruit trees, p. 372-388. In: S.A. Ducolot (ed.). Proc. 16th Intl. Hort. Cong. Gembloux, Belgium.

Shaltout,A.D. and C.R. Unrath. 1983. Rest completion prediction model for 'Starkimson Delicious' apples. J. Amer. Soc. Hort. Sci. 108:957-961.
Swartz, H.J. and L.E. Powell. 1981. The effect of long chilling requirement on time of bud break in apple. Acta Hort. 120:173-178.

Thomson, W.K., D.L. Jones, and D.G. Nicholes. 1975. Effects of dormancy factors on the growth of vegetative buds of young apple trees. Austral. J. Agr. Res. 26:989-996.

Weinberger J.H. 1950. Chilling requirements of peach varieties. Proc. Amer. Soc. Hort. Sci. 56:122-128.

Young, E. 1988. Winter root temperature effects on vegetative budbreak, spur development, and flowering of 'Delicious' apple. J. Amer. Soc. Hort. Sci. 113:301-304.

Young, E. 1992. Timing of high temperature influences chilling negation in dormant apple trees. J. Amer. Soc. Hort. Sci. 117:271-273.

Young, E. J. Dennis, and J. Werner. 1986. 6-BA applied after shoot and/or root chilling and its effect on growth resumption in apple and peach. Hortscience 21:280-281.

Young, E. and D.J. Werner. 1984. Effect of rootstock and scion chilling during rest on resumption of growth in apple and peach. J. Amer. Soc. Hort. Sci. 109:548-551.

Young, E. and D.J. Werner. 1985. Effect of shoot root and shank chilling during rest in apple and peach on growth resumption and carbohydrates. J. Amer. Soc. Hort. Sci. 110:769-774. 